\title{
Restricting extensions to permitted licensing hours does not influence the numbers of alcohol or assault related attendances at an inner city accident and emergency department
}

\author{
Colin A Graham, Lorna S McLeod, David J Steedman
}

\begin{abstract}
Objective-To determine the effect of restricting extensions to permitted licensing hours on the numbers of alcohol or assault related attendances at an inner city accident and emergency (A\&E) department.

Methods-Prospective data collection on consecutive attendances between 17.00 and $09.00 \mathrm{~h}$ during three study periods: two weeks before the introduction of the restriction, two weeks immediately afterwards, and for a two week period beginning five weeks after the change. Blood alcohol concentration was measured with a pocket alcohol meter.

Results-Overall $56.5 \%$ of patients $(n=$ 2836) provided a breath sample, and $28.9 \%$ (819) were positive. The proportion of patients testing positively peaked between 02.00 and $04.00 \mathrm{~h}$. A very high proportion of assault cases who were tested (260) were positive (67.3\%). Assault cases comprised $19.1 \%$ of all attendances between 24.00 and 04.00 h. No significant changes in the pattern of alcohol or assault related attendances followed the restriction in extensions to permitted licensing hours.

Conclusions-A policy of uniform closing times of licensed premises does not influence the profile of alcohol or assault related attendances at an inner city $A \& E$ department.

(F Accid Emerg Med 1998;15:23-25)
\end{abstract}

Keywords: alcohol; assaults; licensing hours

A high proportion of emergency service patients presenting out of hours to inner city accident and emergency (A\&E) departments are affected by alcohol, and many are victims of violent crime. ${ }^{12}$ Despite a review of the relaxation of Scottish licensing laws in the mid-1970s documenting a widespread perception that public drunkenness had become less commonplace, ${ }^{3}$ extensions to permitted hours and lack of uniform closing times can make policing inner city areas more difficult.

Following the Licensing (Scotland) Act (1976), flexible licensing arrangements were introduced allowing licensed establishments to be granted extensions to permitted hours, currently 11 am to $11 \mathrm{pm}$. Since 1993, regular extensions have been granted to licensed premises in central Edinburgh according to their location within a zone. The zoning system had been introduced to restrict late night extensions in noise sensitive residential areas of the city. However, licensed premises can be situated within different zones though in distance terms they are separated by only a few metres. Experience has shown that this creates inequality and more importantly a situation where large numbers of people move from premise to premise in order to be served to the last hour. This situation may contribute to the number of violent incidents in the city centre. The licensing committee of the City of Edinburgh Council, supported by Lothian and Borders police, therefore decided to introduce a uniform closing time in the city with the aim of reducing street violence, public disorder, and demands on the emergency services.

There are 677 licensed public houses in the city, including 165 restaurants with public house licences. After 25 March 1996, all public houses, hotels, and restaurants were required to close by $01.00 \mathrm{~h}$, clubs and public places with entertainment licences by $03.00 \mathrm{~h}$, and casinos by $04.00 \mathrm{~h}$. The aim of this study was to identify any significant differences in the numbers of alcohol or assault related attendances at this city's only adult $\mathrm{A} \& \mathrm{E}$ department following the restriction.

\section{Methods}

Data were collected on consecutive attendances between $17.00 \mathrm{~h}$ and $09.00 \mathrm{~h}$ during three study periods.

(1) Preperiod: Monday, 11 March 1996 to Monday, 25 March 1996.

(2) Postperiod 1: Monday, 25 March 1996 to Monday, 8 April 1996.

(3) Postperiod 2: Monday, 13 May 1996 to Monday, 27 May 1996.

The study therefore ran for two weeks before the introduction of the restriction, two weeks immediately afterwards, and for a two week period beginning five weeks after the change. Data were collected on age, sex, day and time of presentation, mode of arrival, reported location of alcohol consumption before presentation, assault related attendances, and disposal. Blood alcohol concentration was measured indirectly with a calibrated pocket breath Alcolmeter (Lion Labs, Cardiff, UK) and performed by clinical A\&E staff trained in its correct use. Informed consent was sought from all patients participating in the study. There was no attempt for study purposes to identify those 
Table 1 Locus of alcohol consumption

\begin{tabular}{lrl}
\hline & No & $(\%)$ \\
\hline Pub/hotel/restaurant & 351 & $(42.8)$ \\
Club/entertainment licence & 54 & $(6.6)$ \\
Casino & 1 & $(0.1)$ \\
Home & 179 & $(21.9)$ \\
Other & 33 & $(4.0)$ \\
Not known & 171 & $(20.9)$ \\
Denied drinking & 30 & $(3.7)$ \\
Total & 819 & $(100)$
\end{tabular}

patients with a chronic alcohol problem by taking an alcohol history.

Statistical significance $(\mathrm{p}<0.05)$ was determined using $\chi^{2}$ analysis (Pearson test).

\section{Results}

In all, 5023 patients were seen in the $A \& E$ department during the three study periods: preperiod $=1537$ (week $1=742$, week $2=$ 795); postperiod $1=1664$ (week $3=800$, week $4=864$ ); postperiod $2=1822$ (week $5=911$, week $6=911$ ).

Of these, $2187(43.5 \%)$ failed to provide a breath sample, because either they could or would not take the test $(n=284)$, or the workload was such that it could not be performed at the time of presentation $(n=1903)$. Of the 2836 patients $($ preperiod $=1033$, postperiod 1 $=838$, postperiod $2=965$ ) who provided a breath sample, $71.1 \%$ (2017) had no alcohol detected, $7.8 \%$ (222) were positive within the legal driving limit $(80 \mathrm{mg} / 100 \mathrm{ml})$, and $21.1 \%$ (597) were positive over the legal driving limit. The mean blood alcohol concentration (168 $\mathrm{mg} / 1001)$ in those testing positive $(\mathrm{n}=819)$ was twice the legal driving limit. In 98 patients tested (2\%), alcohol intoxication was considered the only reason for their attendance. Men were more likely than women to test positively $(32.6 \% v 21.5 \%)$. Patients aged 40 to 49 years were more likely to test positively $(38.5 \%)$ than patients in any other age group and had the highest mean blood alcohol concentration (205 mg/100 ml).

Patients who tested positively were more likely to say they had been drinking in a $\mathrm{pub} /$ hotel or restaurant $(42.8 \%)$ than in a club or other place with a public entertainment licence $(6.6 \%)$ or at home $(21.9 \%)$ (table 1$)$.

Table 2 Profile of alcohol and assault related attendances before and after the restriction in extensions to licencing hours

\begin{tabular}{lccc}
\hline & Preperiod & Postperiod 1 & Postperiod 2 \\
\hline No (\%) of patients testing positive & $19(30.9)$ & $229(27.3)$ & $\begin{array}{l}271(28.1) \\
\text { NS }\end{array}$ \\
BAC No (\%) & & NS & \\
$<80 \mathrm{mg} / 100 \mathrm{ml}$ & $88(27.6)$ & $61(26.6)$ & $73(269)$ \\
$>80 \mathrm{mg} / 100 \mathrm{ml}$ & $231(72.4)$ & $168(73.4)$ & $198(73.1)$ \\
& & NS & NS \\
No (\%) of patients testing positive attending & & & \\
on: & $154(22.5)$ & $129(22.2)$ & $136(21.3)$ \\
Week nights (Sun-Thur) & $165(473)$ & $100(38.9)$ & $135(41.5)$ \\
Weekend nights (Fri and Sat) & & NS & NS \\
& & & \\
No (\%) patients testing positive attending: & $58(182)$ & $31(135)$ & $40(14.8)$ \\
Before 20.00 h & $119(37.3)$ & $83(36.2)$ & $112(41.3)$ \\
$20.00-24.00 \mathrm{~h}$ & $119(37.3)$ & $94(41.1)$ & $94(34.7)$ \\
$24.00-04.00 \mathrm{~h}$ & $23(7.2)$ & $21(9.2)$ & $25(9.2)$ \\
After 04.00 h & & NS & NS \\
& $125(8.1)$ & $174(10.5)$ & $145(8.0)$ \\
No (\%) of assault related cases & & NS & NS \\
& & & \\
\hline
\end{tabular}

BAC, blood alcohol concentration.

$\chi^{2}$ test ( $v$ preperiod): NS.
In those patients who provided a breath sample, a higher proportion of patients tested positively $(43 \%)$ on weekend (Friday and Saturday) nights than week nights (Sunday to Thursday) (22\%).

Overall the proportion of patients testing positively peaked between 02.00 and $04.00 \mathrm{~h}$, which followed the closure of public houses, hotels, and restaurants at $01.00 \mathrm{~h}$.

Of those patients testing positively, $57.5 \%$ (471) arrived by ambulance, 3\% (25) were under police escort, and $38 \%$ (319) were self referrals; $31 \%$ (253) of those patients with positive breath tests were admitted, $59.5 \%$ (487) were discharged, $7.5 \%$ (61) self discharged, and $1.5 \%$ (12) were escorted from the department by police.

Altogether 444 patients $(8.8 \%)$ were involved in incidents of assault. A third of these (133) involved a weapon. A very high proportion of assault cases who were tested (260) were positive $(67.3 \%)$ compared with $29 \%$ of the whole sample tested. Assault related attendances were more likely to be associated with the youngest patients, particularly those aged 19 years or under (13.4\%) and 20 to 29 years $(12.2 \%)$. The majority of patients involved in assault cases were male $(81.3 \%)$. Overall $39 \%$ of assault cases (174) presented between 24.00 and $0400 \mathrm{~h}$, which comprised $19.1 \%$ of all attendances during that time.

No significant changes in the pattern of alcohol and assault related attendances followed the restriction in licensing hours (table 2). There were no differences in the likelihood of patients testing positively, or in their levels of blood alcohol concentrations. There were no differences with respect to the proportions of patients testing positively and presenting on week nights compared to weekend nights. The restriction did not influence the profile of attendance times for patients with positive blood alcohol results. The change did not influence the levels of assault cases.

\section{Discussion}

The liquor licensing changes which occurred in Scotland in 1976 allowed regular extensions of permitted hours. Although the level of public order offences declined following the liberalisation, this was attributed more to changes in police policy than to the advent of a more relaxed or civilised style of drinking. ${ }^{3}$

During identical time periods to our study, operational staff in the police divisional control rooms covering the city recorded the numbers of incidents of 16 classifications of crimes of violence and public disorder. There were 866 incidents during the two week period before the introduction of the restriction, 1053 in postperiod 1 , and 786 during postperiod 2 . Overall $43.4 \%$ were coded "drink related" but there was no significant difference between time periods (personal communication, Lothian and Borders Police). The impact of restricting extensions to licensing hours on violent street crime and public order offences is difficult to determine. Seasonal trends were not considered and care should be taken before any conclusions are drawn. For example the 
percentage of drink related incidents may in fact normally increase from March to May. There were no extraordinary public events or gatherings during the study periods which could be identified. We are not aware of any problems with enforcement of the restriction or resulting prosecution.

In England and Wales the licensing laws were changed in 1988 by a private member's Bill to allow "all day drinking." A study to assess the impact of these changes on attendances at the A\&E department, Newcastle General Hospital, found no significant changes in overall numbers. ${ }^{4}$ There was, however, a trend towards increased frequency of alcohol ingestion in night time attenders.

The pattern of alcohol or assault related attendances found in this study is similar to that found in other surveys within the United Kingdom. ${ }^{1256}$ A study of the prevalence of alcohol use in patients admitted to this $A \& E$ department was performed by Holt and colleagues in $1979 .{ }^{1}$ In their study, blood alcohol analysis was carried out on 702 patients attending on 17 different nights over a nine month period. Consecutive attendances between 1700 and $0900 \mathrm{~h}$ were examined. The main circumstantial factor influencing the likelihood of alcohol consumption in patients before presentation in Holt's study was the time of attendance, with a greater proportion presenting after midnight and at weekends. The pattern of age and sex distribution and diagnosis in those patients testing positively has remained unchanged. Overall $40 \%$ of patients had consumed alcohol before attending compared to $29 \%$ in our study. This apparent reduction in contrast to an increase in alcohol consumption nationally should be interpreted with caution. A sampling shortfall due to circumstantial factors and patients declining testing could have accounted for this.

We acknowledge that a considerable number of patients did not have a breath sample taken. Given the prevalence of alcohol use among
$\mathrm{A} \& \mathrm{E}$ attenders it is likely that a proportion of these would have been drinking. This would have influenced the results if the proportion had varied between study periods.

The association between alcohol intoxication, violent crime, and associated severity of injury in victims of assault is well established. ${ }^{7}$ The resulting demands on inner city hospital acute services which this study reaffirms can pose difficult management problems. ${ }^{58}$ Prevention campaigns directed at the reduction in these types of incidents are therefore to be welcomed. The report from the Clayson committee which led to the liberalisation of Scottish licensing laws commented that licensing "can play only a strictly limited part in the control of alcohol misuse." Although seasonal trends could have influenced the results, a policy of uniform closing times of licensed premises did not however influence the profile of alcohol and assault related attendances at an inner city $\mathrm{A} \& \mathrm{E}$ department.

We would like to thank all the medical, nursing, and reception staff of the A\&E department, especially Colin Halliday and Sue Muir, for their assistance with this study. We thank Susan McVie and Liz Levy (Scottish Office) for their advice and statistical support. Funding was received from the Scottish Office.

1 Holt S, Stewart IC, Dixon JMJ, Elton RA, Taylor TV, Little $\mathrm{K}$. Alcohol and the emergency service patient. BMJ 1980;281:638-40.

2 Yates DW, Hadfield JM, Peters K Alcohol consumption of patients attending two accident and emergency departpatients attending two accident and emergency depart-
ments in North West England. J R Soc Med 1987;80: ments

3 Duffy JC, Plant MA. Scotland's liquor licensing changes: an assessment. BMJ 1986;292:36-9.

4 Rhodes M, Carlson G, Dunn J, Malata C, Merry C, Milne D. All day drinking-its impact on an accident and emergency department. Health Trends 1990;22:120-1.

5 Taylor CL, Kilbane P, Passmore N, Davies R. Prospective study of alcohol-related admissions in an inner-city hospital. Lancet 1986;ii:265-8.

6 Walsh ME, MacLeod DAD. Breath alcohol analysis in the accident and emergency department. Injury 1983;15:62-6.

7 Shepherd J, Irish M, Scully C, Leslie I. Alcohol intoxication and severity of injury in victims of assault. BMJ 1988;296: and se

8 Robertson CE. Alcohol, trauma and the emergency department. Edinb Med 1989;54:7-9.

9 Clayson C. Report of the committee on Scottish licensing laws. Edinburgh: HMSO, 1972 